\title{
Ethics, Values and Morality in Contemporary Library Classifications ${ }^{\dagger}$
}

\author{
Jens-Erik Mai \\ University of Copenhagen, Royal School of Library and Information Science, \\ Birketinget 6, 2300 Copenhagen, Denmark, <bsh146@iva.ku.dk>
}

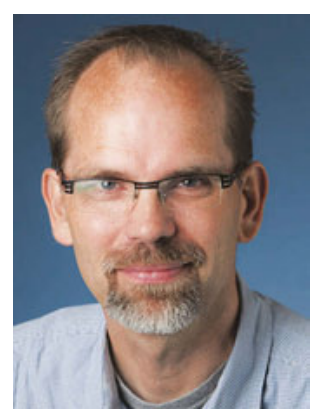

Jens-Erik Mai is professor at the University of Copenhagen, Royal School of Library and Information Science in Denmark. Jens-Erik is interested in basic questions about the nature of information phenomena; he has explored these from a variety of conceptual points (e.g., semiotics, cognitive work analysis, late-modernity, philosophy of language, trust) often with a focus on issues and questions in the organization of information. He has contributed conceptual constructions as well as methodological and programmatic papers that have helped forward thinking about the organization of information. His most recent publications explore contemporary classification theory's conceptual foundation in modernity and the nature of information quality from a pragmatic philosophy of language perspective.

Mai, Jens-Erik. Ethics, Values and Morality in Contemporary Library Classifications. Knowledge Organization. 40(4), 242-253. 43 references.

\begin{abstract}
This paper explores the ethics of classification. The paper outlines recent conceptual moves in knowledge organization research and shows that contemporary classification theory is based on a pragmatic understanding of the world. It suggests that unjust statements and assumptions about the world challenge contemporary library classifications and that a proper response is needed. It outlines a framework for the development of ethical classifications based on MacIntyre's practice-based ethical theory. It provides a framework within which editors and managers of library classifications can make ethically sound decisions.
\end{abstract}

† Earlier versions of this work were presented at the 2nd Milwaukee Conference on the Ethics of Information Organization, University of Wisconsin, Milwaukee, USA in June 2012 and as the author's inaugural lecture for the professorship in information studies at the Royal School of Library and Information Science, Copenhagen, Denmark in September 2012.

Received 19 March 2013; Revised 13 May 2013; Accepted 13 May 2013

\subsection{Introduction: the injustice of classification}

Classifications reflect reality. Reality is biased, unjust, and full of contradictions. One challenge for information professionals-especially for librarians working in large libraries with sizeable and diverse collections and user bases-is to provide access tools that minimize the harm done by classifications. Clare Beghtol once observed that "It is assumed that people engaged in information work prefer ethical to nonethical practices and moral to nonmoral" (Beghtol 2005, 903), implying that information professionals wants to 'do-the-right-thing.' Taking Beghtol's observation together with John Rawls's (1999, 3) reminder that "Justice is the first virtue of social institutions" as basic truths about libraries and librarians, this paper explores the ethical dilemma of library classifications in contemporary society and outlines a conceptual foundation for ethical responsible management of library classifications in the diverse, multi-cultural society of today.

Classification has been based in modernity's hope for universality and objective representations; the aim has been to classify and represent things as they really are (Mai 2011). However, given recent decades' critiques of modernity and explorations into the contextuality and locality of human experiences, many contemporary conceptualizations argue that classification ought to be considered relative, tied to specific temporal and spatial constraints, as, for instance, Geoffrey Bowker and Susan Leigh Star $(1999,10)$ do, when they define classification as, "a spatial, temporal, or spatio-temporal segmentation of the world." Bowker and Star demonstrate how classifications penetrate science, society, and culture and how classifications have become invisible. In drawing on ex- 
amples of classifications of diseases, viruses, tuberculosis, race, and nursing work, they show that many, perhaps all, classifications at the surface may look innocent and perfectly fine, and that on close inspections all classifications reveal real consequences and assumptions about the world; however, as they note, classifications might "as with many strange things ... become well adopted to the modern bureaucracy" (Bowker and Star 1999, 131). To understand the basic assumptions hidden in classifications, Bowker and Star $(1999,131)$ argue that we need to bring classifications out of their contexts, because "classifications that appear natural, eloquent, and homogenous within a given human context appear forced and heterogeneous outside that context" - and only outside their contexts will the forced nature of classifications be revealed. As such, they urge a re-thinking of classifications: "Classifications are powerful technologies. Embedded in working infrastructures they become relatively invisible without losing any of that power ... classifications should be recognized as the significant site of political and ethical work that they are. They should be reclassified" (Bowker and Star 1999, 319). Bowker and Star's descriptive approach opens up for an understanding of classifications where classifications play political, ethical, societal roles and are not viewed merely as neutral tools used to perform a job.

While there have been some late-modern critiques of library classification's colonialistic approach to dealing with issues of diversity and conflicting worldviews (e.g., Berman 1971; Olson 2002), this paper takes those critiques one step further and asks: how do we deal with relativity in classification, how do we develop and maintain classifications in the late-modern society? The paper will ultimately offer a conceptual framework for making ethical decisions when editing and managing library classifications. The paper builds on previous explorations of library classifications' ethical challenges and offers solutions and a path forward for how library classifications could handle issues of diversity and conflicting worldviews in the contemporary multi-cultural world.

One current pressing challenge for library classifications is to address the fundamental issue of how to handle ethical and moral issues in contemporary classifications of information. By asking such questions, the paper seeks to push the ethical, political, and societal issues embedded in library classifications to the forefront of the conversation. This necessitates changes in the conversation about classifications; it requires a re-classification of library classifications from being thought of as neutral, hidden, embedded tools to being sites that expose assumptions and perspectives on the world and society. This emphasizes the forced nature of library classifications. This change furthermore requires a revision of so- ciety's understanding of libraries as neutral and independent spaces for intellectual and personal inquiry, a revision of education of library professionals to emphasize the epistemological nature of classifications, and it challenges scholars to work out approaches to classification that view library classifications as epistemic objects.

Until recently the field was more or less founded on a position akin to naïve realism. As Francis Miksa (1998, $81,139)$ discusses in his book on the history of library classification theory, it was the goal and hope for many decades that, "somewhere, somehow, we can, or should try to, produce the one best classification system that will serve all purposes" with "the ideal of achieving international bibliographic control." The goal was to develop classification systems that reflected the universe of knowledge. It was assumed that the universe of knowledge exists independently of human perception and specific cultures, and that it is accessible to humans. While the idea has deep philosophical roots, in the library world the idea goes back to Melvin Dewey's Eureka! moment that Sunday morning during a long sermon (Wiegand 1996; 1998).

Dewey's idea was a practical solution to a customer service problem; at the time, a book would have different call numbers in different libraries - this was confusing to patrons. Instead, he suggested, call numbers should be constructed according to the book's topic's placement in the universe of knowledge and not according to the book's physical placement in libraries. A book would then have the same call number no matter which library the book was placed in. The degree to which a book's call number fits the content does not come into play in this tradition; either the call number is correct or it is not, either the book is about a certain concept or idea in the universe of knowledge or it is not. There is no room for interpretation, user-centeredness, domain specificity, or cultural differences in this tradition. The notion of the university of knowledge has many advantages, including the fact that libraries could more easily share material and the whole enterprise could be industrialized.

Regardless of the notion of the university of knowledge makes sense from a practical point of view, it is based on a flawed conceptual basis. The notion that there is such a thing as the universe of knowledge has been challenged many times in contemporary philosophy and most recent work in classification rejects the notion. Most scholars accept that there are multiple universes of knowledge, that people come to the world from different perspectives, view the world differently, and understand the world differently. Further, most scholars today accept that things and topics cannot be classified independently from their function, interpretation, use or relation to other things and topics - it is generally accepted that things and topics do not have innate essences. In this line 
of thought, things and topics make sense only within specific contexts, and they are always understood from a particular epistemic standpoint.

These more recent explorations have repositioned mainstream theory of knowledge organization to align it with contemporary social oriented theories of meaning, information, and activities. One purpose of this project of realignment has been to advocate a 'relativistic' understanding of classification and to argue that a classification can only be developed, evaluated and judged from within specific social and cultural contexts. As Patrick Wilson $(1983,165)$ once pointed out, to change how libraries are organized, we first need to 'admit' that the world can viewed from many different perspectives:

If we admit that the number of different perspectives from which the world can be viewed and described is endless, we shall expect that the library to contain competing, conflicting accounts of the world that cannot be incorporated into a single consistent story of the way things are.

Instead of aiming for the one best system for all purposes, independent of space and time, the aim of this 'relativistic' approach is to highlight the importance of culture and context for classifications. This has emphasized the impossibility of creating the one best system and showed that understandings and meaning is contextdependent. In this sense, a classification can only be judged against the purpose for which it is created and used; as Dupré $(2006,30)$ noted, "Classifications are good or bad for particular purposes, and different purposes will motivate different classifications." In this sense, what is important are the epistemological and ontological positions that a classification takes and that creators and maintainers of classifications are responsible for the choices and decisions made in the particular classification. In this sense, all classifications are biased, because they express particular views on the subject matter. This, however, should not be seen as a problem, but rather as a fundamental fact about classifications; "the DDC, or any classification, is not problematic if it expresses a point of view on the subject matter that it organizes. Indeed, there is no way it can avoid doing so" (Feinberg 2011, 7). Any given classification, therefore, inevitably privileges or brings into more prominence some concepts, perspectives, experiences, viewpoints or issues, and marginalizes or moves out of view others. In this sense, any act of classification unavoidably fails to do justice to at least some dimensions of that which is classified.

The challenge for-and peculiar responsibility oflibrary classifications is that library users may look to the classification as an authoritative statement on the rela- tions between different subjects. While this may not be a challenging issue for uncontroversial issues, it does present an ethical dilemma when the issue is one where no consensus is formed or is controversial. Brubaker (2002, $20,28)$ discusses challenges that arise "when cataloging works whose authorship and authenticity is in question," and she found that ethical dilemmas might develop "since the catalog user may look to our records as an authoritative statement." Brubaker's discussion is of interest, precisely because she "concentrates mainly on those [issues] for which consensus on an ethical response may be hard to achieve" (Beghtol 2008, 16). It is those problems for which professional codes, rules, and guidelines are not "designed to deal with" (Beghtol 2008, 16) that are of interest, because "how library professionals respond to their ethical dilemmas directly affects their ability to carry out their mission" (Fallis 2007, 32). Library professionals are clearly in need of guidance on how to handle situations where different values are in conflict.

While the last couple of decades of inquiries into knowledge organization have refocused the conceptual foundation of the field, it has failed to provide for a sound ethical theory of classification. In this paper, I will argue for a reposition of the foundation of classification from ontic and epistemic questions to one based in moral philosophy. The starting point for this exploration will be to suggest that instead of merely asking about the nature of that which is classified (as in ontological based approaches) or asking what we know about that which is classified (as in epistemological based approaches), we should also include considerations of what it means to create just, fair, and good library classifications.

\subsection{Ethics in the library}

The best place to start an exploration of ethics in libraries and library classification is with IFLA's Glasgow Declaration on Libraries, Information Services and Intellectual Freedom (IFLA 2002) and ALA's Code of Ethics of the American Library Association (ALA 2008), since these codes of ethics are put in place to guide libraries and librarians in situations where they face ethical dilemmas.

ALA's (2008) code is quite precise in its observation that:

Ethical dilemmas occur when values are in conflict. The American Library Association Code of Ethics states the values to which we are committed, and embodies the ethical responsibilities of the profession in this changing information environment. 
Librarians do face situations where different sets of value are in conflict; the goal of the code of ethics is to guide librarians in making the right decision:

The principles of this Code are expressed in broad statements to guide ethical decision making. These statements provide a framework; they cannot and do not dictate conduct to cover particular situations.

While the code of ethics cannot be a list of answers of how to act in each ethical dilemma a librarian might face, the goal is to provide a framework within which the librarian can make informed ethical decisions. The presumed aim is that a librarian when facing a conflict in value can consult the code of ethics, which will provide a framework within which the librarian can make the right decision. The underlying assumption of ALA's Code is similar to Beghtol's observation mentioned above that "people engaged in information work prefer ethical to nonethical practices and moral to nonmoral" (Beghtol 2005, 903) - the assumption seems to be that there is a clear distinction between ethical and unethical decisions, between what is right and what is wrong. We will see the distinction might not be as clear-cut; it might be that the distinction is context- and culture-dependent.

The IFLA declaration is not as explicit as ALA about the purpose of its code of ethics and how it should be used. The declaration states that it is based on the notion of "intellectual freedom as expressed in the United $\mathrm{Na}$ tions Universal Declaration of Human Rights" (IFLA 2002) and affirms that: "IFLA therefore calls upon libraries and information services and their staff to uphold and promote the principles of intellectual freedom and to provide uninhibited access to information."

While the notion of "intellectual freedom" is not explicitly included in the United Nations Universal Declaration of Human Rights, ${ }^{1}$ the notion of "uninhibited access to information" remains strangely vague in this context; does this include access to personal information, hate speech, defamation, child pornography, and state secrets? Without some overarching guiding moral principles, it is difficult to appreciate the notion of "uninhibited access to information." It must be assumed that IFLA only promotes uninhibited access to certain kinds of information-the demarcation of which information to provide access to and which to censor is the challenging ethical dilemma at play here. IFLA does not provide help in making that distinction. Furthermore, and to complicate matters, even if IFLA explicitly omitted personal information, hate speech, defamation, child pornography, and state secrets from the kind of information to which libraries should provide uninhibited access, someone needs to decide whether particular items are in fact personal information, hate speech, defamation, child pornography, or state secrets. Most people would accept that libraries should provide uninhibited access to the kind of information that should flow freely in democratic societies, and most people would accept that certain information should be censored and kept out of reach. While it may have been IFLA's intention to say precisely that, "it would certainly be better to have a statement of principles that better matches the intent of librarians" (Fricke et al. $2000,477)$. It may, at the end, be more harmful than beneficial to have a code of ethics that simply states that libraries should "provide uninhibited access to information" (IFLA 2002), when, in fact, they should only provide uninhibited access to some information; how do we as a society entrust librarians to select and censor which information to be included in our libraries when the selection is not guided by a proper ethical framework?

While both codes of ethics cover a wide range of issues in information ethics, including statements on intellectual property, privacy, intellectual freedom, censorship, democratic values, civil right, etc., for the purpose of this paper, we will focus on the statements that speak most directly to the ethical issues in knowledge organization.

In the ALA Code of Ethics (2008), there are two statements that are especially relevant. The first being:

1. We provide the highest level of service to all library users through appropriate and usefully organized resources; equitable service policies; equitable access; and accurate, unbiased, and courteous responses to all requests.

This principle advocates the notion that "resources" should be organized in an "appropriate and useful" manner for "all library users." It does not discuss how this is done. The assumption seems to be that there is a way in which all resources in a library can be organized in such a manner that it becomes useful for all users; that information can be organized "unbiased" and "courteous" to all responses. As noted above, most contemporary scholarship in classification takes a different stand; it advocates that all classifications are inherently biased (e.g., Olson 2002; Feinberg 2012).

The second statement that is relevant for the purpose of this paper is (ALA 2008): "7. We distinguish between our personal convictions and professional duties and do not allow our personal beliefs to interfere with fair representation of the aims of our institutions or the provision of access to their information resources." The explicit assumption here that a person's convictions are made up of those convictions that are purely private and those convictions that are professional-and that it is possible to 
separate the two. It assumes that someone can separate their private homophobic, sexist, ignorant, and racist convictions from their professional behavior. It assumes that one's knowledge and belief structures are made up of a section for private thoughts and a section for professional thoughts. While it is well to assume that librarians are able to separate their private convictions from their professional duties and leave their prejudices at the doorstep, ALA's code of ethics does not explain how this separation of convictions is achieved or provide a convincing suggestion for how librarians are or should be able to separate the two kinds of convictions.

Both of these ALA statements are in line with the basic assumption underlying modern librarianship - that libraries and librarians should embrace the position of neutrality. Within this assumption of neutrality and objectivity, ALA's "guide [to] ethical decision making" (ALA 2008) is constrained to suggest that librarians do-theright-thing when facing an ethical dilemma.

IFLA's Glasgow Declaration on Libraries, Information Services and Intellectual Freedom (IFLA 2002) is as vague in its recommendations as ALA's code of ethics, but in a slightly different way. IFLA's declaration is based on the notion of intellectual freedom, which it takes to be "the fundamental right of human beings both to access and to express information without restriction" and it "encompasses the wealth of human knowledge, opinion, creative thought and intellectual activity" (IFLA 2002). The declaration adheres to a notion of freedom to information that pertains beyond conventional privacy and state secrecy standards. It goes as far as claiming that this notion of intellectual freedom "is a core responsibility of the library and information profession worldwide, expressed through codes of ethics and demonstrated through practice" (IFLA 2002).

Like the ALA Code of Ethics, IFLA's Glasgow Declaration on Libraries, Information Services and Intellectual Freedom contains a number of statements, five in total. This paper will focus on two of those. The first being:

\section{Libraries and information services shall acquire, preserve and make available the widest variety of materials, reflecting the plurality and diversity of society. The selection and availability of library ma- terials and services shall be governed by profes- sional considerations and not by political, moral and religious views.}

The aim here is, on one hand, to reflect the plurality and diversity of society and, on the other hand, not to take side in that plurality and diversity. The aim is, as Wilson $(1983,190)$ said, that librarians have "no politics, no religion, and no morals" and that libraries demonstrate "complete hospitality to all opinion." The principle is one of "studied neutrality; the librarian is professionally noncommittal" (Wilson 1983, 190). In practice, this principle is, of course, unattainable. Values do come in conflict in the library. Librarians do make decisions about which material to provide access to, how to classify that material, and which terms to use when naming ideas and subject matter. There is no view from nowhere. Any act of naming or classifying is an act of saying something about the world, and such an act is always done from a particular perspective. The ethics at play in IFLA's declaration is one that "tell us only not to aim at evil; they don't tell us to aim at good, as a means" (Nagel 1986, 181). It assumes that an ethics free of any moral standpoint is a good ethics; an ethics that aims for what is objectively best for everyone. However, the plurality and diversity of the real world demand that any idea or subject matter can be approached ethically correct and understood epistemological sound from many different equally correct viewpoints. In such an ethics it is, according to Ess $(2009,21)$ :

possible to see that different views may emerge as diverse interpretations or applications of shared norms, beliefs, practices, etc. Insofar as we can discern that this is so, the differences between two (or more) views thus do not force us to accept only one view as right and all the others as wrong. Rather, we can thereby see that many (but not necessarily all) different views may be right, insofar as they function as diverse interpretations and applications of shared norms and values.

The world is pluralistic and diverse, and an ethically responsible response to such a world is an ethics that celebrates that plurality and diversity, not one that demands one's ethics to be superior-even if that ethics is claimed to be neutral and objective, for even that ethics is an ethics from a particular view.

The second statement in the IFLA (2002) declaration that is relevant for this paper is:

4. Libraries and information services shall make materials, facilities and services equally accessible to all users. There shall be no discrimination for any reason including race, national or ethnic origin, gender or sexual preference, age, disability, religion, or political beliefs.

The objective of this statement is to commit libraries to be value-free institutions. Libraries are encouraged to aim at being institutions in which all opinions are welcome, all beliefs are welcome, and where all people feel included, represented, and welcome. It is a library where Christian- 
ity is both the dominating religion and where it is not, where race is highlighted as something that separates us and where race is absent, where homosexuality is a choice and where it not, where abortion is both a crime and legal, where prostitution is both immoral and an accepted occupation, where Vikings are both heroes and villains, and where Palestine is a state and does not exist at the same time. This is a fiction. Libraries and librarians must make choices. In the world of books, ideas, and arguments, different values are at play and in naming and classifying them, choices are made. While it would be nice and good to take the position of no-position and thereby eliminating bias, reality is that there is no no-position-in the real world, all statements are uttered from a particular position in the world. And people do disagree about how to understand the world; "the closer the neighbours the sharper the conflict" (Broadfield 1946, 69).

The prospect of eliminating bias has a long history in the library literature; in her review of literature on bias in classifications, Feinberg (2008, 25-26) concludes that

The majority of research on bias and classification maintains that it is a negative, exclusionary force, and either wants to remove it or fix it. Bias is the sneaky enemy of equity and fairness, and it is important at the least to expose it and be wary of it. In a similar vein, most of the work on bias emphasizes the exclusion of non-dominant or less powerful interests. However, with such characterizations of bias, changes made to eliminate bias (to make situations more fair) are themselves susceptible to similar charges of bias.

Where IFLA sees the elimination of bias as a path toward a view from nowhere, Feinberg sees the elimination of bias as the creation of another bias; instead of aiming to create value-free classifications, the aim ought to be to work with the realization that "all systems will exclude or marginalize in some way" (Feinberg 2008, 26). If the assumption that all classifications inhibit a particular view, the starting point would be "to in some sense embrace bias and make the most of it" (Feinberg 2008, 26) and as Wilson (1983) urged: admit that the world can viewed from many different equally correct and valid perspectives. In this context, from this perspective, it is quite naive and unhelpful for the IFLA declaration to encourage "no discrimination for any reason" (IFLA 2002) in the library, because all systems do discriminate; "all classifications will express a point of view on a subject" (Feinberg 2008, 26).

While both IFLA and ALA accept that there are conflicting values at play in the library and that there may in principle be more correct ways to address an issue, they fail to accept this insight as the foundation for their ethics. Fricke, Mathiesen, and Fallis (2000) suggest that fallibilism ought to frame ethics in the library. Fallibilism is the basic and well-accepted view that one must accept that, despite the best intentions and available information, one's ideas, theories, virtues, and notions may be mistaken (Cohen 1988; Reed 2002). Fricke, Mathiesen, and Fallis (2000, 468) write:

The ALA's response to fallibilism is to propose that we not make any judgments of choices or decisions at all. They wish not to censor anything, not to label anything, not to deny anyone access, and never act paternally. Presumably this is because they believe that this strategy will allow them to avoid error (and a number of practical headaches). This response is a mistake.

In the realization that librarians might make wrong decisions, because all decisions could potentially be proven wrong, the recommendation by IFLA and ALA is that librarians remain neutral and do not make decisions. The challenge, of course, is that this is impractical and impossible; the very act of being a librarian and working with information and ideas entails that one make decisionsand knowing that these decisions could be wrong. Libraries and librarians need to take their ethical responsibility seriously and ground their work in solid conceptual frameworks.

\subsection{Two examples}

Two examples form the knowledge organization literature will help ground these discussions in contemporary library classification. The first example is about race and the second about religion in the Dewey Decimal Classification (DDC). Both examples are used here to highlight the discussions and language used when dealing with ethical dilemmas in the knowledge organization literature; the examples are not used to evaluate current practice per se. Both examples are a few years old, because there are very few discussions about practical ethical issues in the knowledge organization literature.

With the outset in the elimination of race from Table 5 , Furner (2007) discusses the place of race in the $21^{\text {st }}$ edition of DDC. Until the change, Table 5 in the DDC was named "Racial, ethnic, and national groups" and, after the change, race was dropped from the Table, and it was renamed: "Ethnic and national groups."2 While race was an option in Table 5, until 2003, it allowed for these, somewhat outdated, categories of race: 


\begin{tabular}{|l|l|}
\hline-03 & Basic races \\
\hline-034 & Caucasoids \\
\hline-035 & Mongoloids \\
\hline-036 & Negroids \\
\hline-04 & Mixtures of basic races \\
\hline-042 & Caucasoids and Mongoloids \\
\hline-043 & Mongoloids and Negroids \\
\hline-044 & Negroids and Caucasoids \\
\hline-046 & Caucasoids, Mongoloids, Negroids \\
\hline
\end{tabular}

Table 1. Extract from Table 5, "Racial, Ethnic, National Groups,” DDC 21st edition, 1996 (Furner 2007, 156)

The motivation for the change is "to reflect the deemphasis on race in current scholarship" (Mitchell et al. 2003 cited in Furner 2007, 156), which has the effect, as Furner comments, that "it seems almost as if the human populations that are typically referred to as 'races' are no longer available as subject matter for writers" (Furner 2007, 156). In an attempt to act ethically responsible by eliminating the notion of race from our vocabulary, in the hopes of de-emphasizing race in current political discourse, DDC ends up taking a problematic ethical position on the issue of race. Especially considering the fact that books continue to be written on race, and these books need to be classified in the system; a new rule is therefore invented by the $D D C$ in which works on race are now "classed with the ethnic group that most closely matches" (Mitchell et al. 2003 cited in Furner 2007, 156). This implies that "any population defined in the work by racial characteristics should be treated, for classification purposes, as a group whose commonality resides in their ethnic (i.e., sociocultural) heritage" (Furner 2007, 156).

While it is obvious that the 1996 DDC terms for race are problematic in contemporary discourse, it appears that the ethical framework guiding the decision to eliminate race altogether (and equating race with ethnicity) is as problematic as terms of the past. As Geoff Nunberg once observed in his discussion of the use of the word "Caucasian" in American media: "confusion is endemic in the American language of race. We're always struggling to find racial labels that answer the question 'what are you' with even-handed essences, but the labels keep catching their sleeves on disparities in the way we think about race itself. Racial classifications are like irregular verbs-they may be inconsistent, but they run too deep to be eliminated by decree" (Nunberg 2004, 16).
The other example is the 200 section in DDC, the religion section:

\begin{tabular}{|l|l|}
\hline 210 & Philosophy \& theory of religion \\
\hline 220 & The Bible \\
\hline 230 & Christianity \& Christian theology \\
\hline 240 & Christian practices \& observances \\
\hline 250 & Christian pastoral practice \& religious orders \\
\hline 260 & Christian organization, social work \& worship \\
\hline 270 & History of Christianity \\
\hline 280 & Christian denominations \\
\hline 290 & Other religions \\
\hline
\end{tabular}

Table 2. Section 200: Religion in DDC 23

As Clay Shirky commented in 2005: "How much is this not the categorization you want in the $21^{\text {st }}$ century?" (Shirky 2005). The editors of DDC are, of course, aware of this, as they noted in a blog post in 2006, "We're the first to admit that the top-level view of 200 Religion in the DDC is problematic" (Green 2006) and based on this realization, they embarked on a study "about the future structure of 200 Religion" (Green 2006). The DDC editors sought inspiration with editors of the Universal Decimal Classification (UDC), because both "systems are historically rooted in a firm Christian tradition and each has attempted to accommodate itself to the modern world in the recent past" (McIlwaine and Mitchell 2006, 323). The challenge is seen as one where non-Christian religions are accommodated into a Christian system by moving, relocating, and integrating categories dedicated to the Christian faith to "reduce the Christian bias" (Mcllwaine and Mitchell 2006, 323). The primary goal of the exercise is to provide improved "mappings" (McIlwaine and Mitchell 2006, 330) between the two systems. It is not an exercise in making ethicalbased decisions to ensure that faiths are represented in a responsible and fair manner. The question is, of course, what would a responsible and fair manner look like; as David Weinberger $(2007,56)$ once observed:

Imagine that the system's editors decide to fix the system once for all .... They consolidate the Christian topics, pull Buddhism up a couple of integers, push Baha'i down .... The Sunnis and Shiites are upset because they've been put at the same level. The Jews are furious because the Jews for Jesus, whom they view as Christian predators, are listed under Judaism. Librarians are out buying razor blades in bulk and white ink by the gallon.

The simple point is that, of course it is not possible to 'fix' the system. The system will always contain a bias of 
some sort. The question is what kind of bias is accepted; as $\mathrm{Oh}$ and Yeo $(2001,83)$ argued, the main challenge is to "enable libraries to arrange many religions by giving them almost equal preferred treatment." While Oh and Yeo's focus is on countries where no single religion dominates, it should be considered whether religions ought not to be represented more equally even in countries that have "a firm Christian tradition" (McIlwaine and Mitchell 2006, 323). Perhaps libraries and librarians need to consider whether the notion of merely accommodating nonChristian religions into classification systems is at odds with the fundamental notion of "appropriate and usefully organized resources; equitable service policies; equitable access; and accurate, unbiased, and courteous responses to all requests" (ALA 2008)?

The main challenge is not necessarily merely to reduce the Christian dominance, but to articulate a vision for the system; is the system merely a tool used to mark and park? Or, is it acknowledged that the system is active in the construction of knowledge in the library? Do librarians recognize that the classification system is the main infrastructure of libraries and, as such, is a "site of political and ethical work" (Bowker and Star 1999, 319)? These questions require, though, that the "common dictum ... that classification should not be critical" (Broadfield $1946,78)$ is questioned and that it be accepted that, "whatever precautions a classification may take, it will be critical. For it is a system of expressed judgments" (Broadfield 1946, 78). There is no way to avoid making ethical decisions in the library.

\subsection{Framework for ethical classifications}

A framework for ethical responsible classifications in contemporary libraries must recognize that "codes of professional ethics can help provide [guidance on ethical decision-making], but they are not sufficient" (Fallis 2007, 32). The ethical foundation of classification work must be found elsewhere. It must furthermore be recognized that in the library, as Hjørland (2004b, 86) writes:

Some kinds of bias are unavoidable, but this should not be regarded as problematic as long as social and cultural awareness and responsibility are considered in their construction. The important thing is to bring pragmatic and ethical criteria into the heart of LIS.

As theories on knowledge organization have moved away from the objectivistic and essentialistic notion of the universe of knowledge and its focus on the one, best system, the notion of domains and domain-analysis has gained ground. Domain-analysis replaces the goal of creating classifications that work for everyone in all situations, with the notion that it is the particular that is of importance; that information is best organized in accordance with the practices in specific domains. Hjørland and Albrechtsen (1995, 400) formulated the domain-analytic principle as

The domain-analytic paradigm in information science (IS) states that the best way to understand information in IS is to study the knowledge-domains as thought or discourse communities, which are parts of society's division of labor. Knowledge organization, structure, cooperation patterns, language and communication forms, information systems, and relevance criteria are reflections of the objects of the work of these communities and of their role in society. The individual person's psychology, knowledge, information needs, and subjective relevance criteria should be seen in this perspective.

The basic point is that epistemological decisions should be taken in the shared space of the domain. Likewise, ethical decisions should be taken in the same, shared space. Libraries and librarians should free themselves from senseless notions of neutrality and objectivity and instead seek epistemological and ethical guidance in the practice of the domains.

\subsection{The problem with ethics}

For most people who have never dealt with moral philosophy, ethics is often thought of as a number of imperatives; statements on what is right and what is wrong. The idea is that there are absolute moral rules, statements that are true for everyone regardless of time, place, and situation. The most common is: "do not lie." And, yes, it is easy to think up situations where it is correct to lie; like when a murderer inquires about your neighbor's whereabouts. This kind of ethics is often associated with Kantian ethics, about which MacIntyre once observed (1998, 190), "For many who have never heard of philosophy, let alone of Kant, morality is roughly what Kant said it was." The basic position is that there is a right way to act in any situation, which is often: "do the right thing." "Do the right thing' is a moral principle we all believe in, which admits no exceptions. We should always do what is right. However, this rule is so formal that it is trivial-we believe it because it doesn't really say anything" (Rachels and Rachels 2012, 133). As we saw above; the "do-theright-thing" ethical principle is the primary ethical stance of the ALA code of ethics.

A second common response to ethics is the opposite stand - that there are no universal rules, that ethics and morality are relative to particular cultures. The idea that 
what is right and wrong is something that can only be determined within cultural bounds because "different societies have different moral codes" making it "arrogant for us to judge other cultures" (Rachels and Rachels 2012, 27-28). Within such an ethics, it is impossible to judge the morality of any act or statement, instead "tolerance ... appears to emerge as itself a universally valid ethical norm or value" (Ess 2009, 184). This, of course, creates a fundamental contradiction: "if all ethical values ... are indeed valid or legitimate only in relation to a given culture or time, then it would seem that tolerance must likewise count as only a relative value" (Ess 2009, 184). In this complete relativistic position, it is impossible to take any ethical standpoint; it is impossible to judge any act or statement as moral or immoral, because all acts and statements are products of their specific cultures and times about which we can make not ethical judgments.

Both of these meta-ethical standpoints are unsatisfactory when it comes to library classifications. In an absolutistic approach, library classifications, like the $D D C$, would rise to an ethical authority that states what is right and wrong; it is doubtful whether library classification has or should have that sort of cognitive authority. In a cultural relativistic position, it would be impossible to evaluate the ethical stance of a library classification because it could merely claim a particular cultural position, free of other discourses. In both situations, library classifications would be free of any responsibility to facts, reality, and people. And in both situations classifications are merely expressions of the editors' personal opinions; they would not be responsible to objective criteria and truth.

It is sometimes assumed that "the world is exhausted by what is the case. ... But the physical world contains only is and not ought. So there is no fact making ethical commitments true" (Blackburn 2001, 26), assuming that "factual judgments are true or false" whereas "moral judgments [are] expressions of attitude of feeling, and neither true or false" (MacIntyre 2007, 12). Such an approach to ethics separates factual judgments, which can be true or false, from moral judgments that are neither true nor false but merely expressions of preference. This has created a split between what is and what ought to be. This line of thinking of is largely a product of modernity in which the world is taken to be what it is and where humans have free will to choose to be what they want. The result is an ethical emotionism in which reactions to moral statements merely are "Wow, terrific, if that works for you that's great!," "Well, that's just your opinion!," and "If they do it that way, that's no business of mine!." But, as Blackburn (2001, 25) writes, "an ethical conversation is not like 'I like ice-cream,' 'I don't,' where the difference doesn't matter. It is like 'do this,' 'don't do this,' where the difference is disagreement and does matter."
To move the evaluation of ethical judgments from a purely personal sphere in which "there are and can be no valid rational justification” (MacIntyre 2007, 19) to a rational ground in which there can be objective disagreements that matter, we need to found the ethics of classification within a teleological framework and in "the practice as providing the arena in which the virtues are exhibited" (MacIntyre 2007, 187). In this arena of practice, there is right and wrong, and ethical statements can be evaluated against the standards of the particular practice.

\subsection{A practice based ethics}

The goal for a practice-based ethics is to free ethics from dogmatic views in which ethics are given by an allknowing authority independent of time and place, and from cultural relativistic views in which ethics have lost meaning and the world has become a moral free-for-all, and from passion and emotions in which ethics is purely in the eyes-of-the-beholder. The goal is to allow moral judgments to be factual statements that matter and about which there can be disagreements. According to MacIntyre $(2007,59)$, this can be achieved by placing ethics in the Aristotelian tradition:

Within the Aristotelian tradition to call $x$ (where $x$ may be among other things a person or an animal or a policy or a state of affairs) good is to say that it is the kind of $x$ which someone would choose who wanted an $x$ for the purpose for which $x$ 's are characteristically wanted.

The presumption is that, within such a framework, it can objectively be right or wrong to call something good, because that is a matter of fact within a specific tradition, purpose, or function. MacIntyre (2007, 59) continues: "To call something good therefore is also to make a factual statement. To call a particular action just or right is to say that it is what a good man would do in such a situation; hence this type of statement too is factual."

Within this tradition, ethical statements are statements of facts; they can be evaluated to be right or wrong independently of personal feelings and passions and without requiring an all-knowing authority. Furthermore, they are bound by shared, common practices within which meaning and facts are established. Placing the ethics of classification within this tradition, allows us to judge whether a classification is good or just as a factual statement.

The foundational element in this ethics is the notion of practice, "By practice I am going to mean any coherent and complex form of socially established cooperative human activity through which goods internal to that form of activity are realized" (MacIntyre 2007, 187). In this sense 
of practice, practice is something in which humans collaborating together achieve something beyond themselves; something that can only be achieved by immersing in a greater system. It is not solely people collaborating on a task; that task needs to be embedded in a greater collective practice. Therefore "tic-tac-toe," "throwing a football with skill," "bricklaying," and "planting tulips" (MacIntyre 2007, 187) are not examples of practice in this sense. Whereas a "game of football," "chess," "architecture," "faming," "enquiries of physics, chemistry and biology," "work of historian," "painting," and "music," on the other hand, are examples of practices (MacIntyre 2007, 187).

Common for these practices is a "certain kind of relationship between those who participate in" (MacIntyre 2007, 191) that which defines the practice. One fundamental part of that relationship is that participants "have to accept as necessary components of any practice with internal goods and standards of excellence the virtues of justice, courage, and honesty" (MacIntyre 2007, 191). This conception of practice is well known within knowledge organization research, as it is quite close in its conceptualization to the domain-analytic approach to information science advocated by Birger Hjørland and others (e.g., Tennis 2003; Hjørland 2004a; Mai 2005; Talja 2005). Just like domains within information science should not be confused with scholarly disciplines, "practice must not be confused with institutions” (MacIntyre 2007, 194).

In formulating an ethics for classification, the key component is that the practice itself, as a collective whole, sets the ethical standards for the practice. When judging whether an act or statement is right or wrong, it must be done against the practice's own internal goods. According to MacIntyre (2007, 190): "A practice involves standards of excellence and obedience to rules as well as the achievement of goods. To enter into a practice is to accept the authority of those standards and the inadequacy of my own performance as judged by them."

When one has entered a practice, one has accepted the language of that community, and, at the same time, also accepted its standards, history, and ethics. While it is possible to disagree with the practice's standards and ethics, this disagreement must come from within the practice and be based on the accepted norms in the practice. One cannot challenge the norms of a practice without first acknowledging the authority within the practice. A challenge of the norms must come from within the practice's current norms and hence its current language, standards, and ethics.

The challenge of norms is therefore one that is rational and based on established objective criteria; it is not a matter of: "I like ice-cream," "I don't," because "In the realm of practices the authority of both goods and standards operates in such a way as to rule out all subjectivist and emotivist analyses of judgment" (MacIntyre 2007, 190). This allows for an ethics that is based on rational arguments, and it allows for disagreements based on objective interpretations of the practice and not on personal preferences and emotions.

Within this framework, ethics has been grounded in the practice, and ethical judgments can be made on rational and objective bases. By placing the ethics of classification within this framework, to call a particular classification good or right is to say that it is the kind of classification that someone would choose who wanted a classification for the purpose for which this particular classification is characteristically wanted within a particular practice. It is thereby possible to objectively evaluate the ethical sensibilities of a given classification. For a classification to be just or good, the classification must be based in a practice (aka a domain) and not bound to particular institutions. The classification must actively seek engagement and justification in the activities and judgment of the practice. It must furthermore be in accord with the internal goods and standards of that practice; in the situations where the classification differs from the standard and authority of the practice, it must do so explicitly and with justification and explanation. This requires that editors and managers of classifications are conscious about their ethical and epistemological decisions.

\subsection{Conclusion}

The ontological and epistemological foundation for classification work has, in recent years, moved from an essentialistic conception of a universe of knowledge to a pluralistic, pragmatic view of domains and practice as its foundation. Unfortunately, the practice of classification has been slow in catching up with this change in scholarship, which results in the ill-fated situation that libraries have been caught with unjust and ethical problematic classification tools. As libraries and librarians address this situation and rework the classifications of yesteryear, a proper theoretical foundation for this work is needed.

Bowker and Star (1999) argued that classifications should be reclassified from neutral, hidden tools to sites of political and ethical work-library classifications are not exempt from this charge. Libraries and library classifications can no longer call to neutrality and independence; they engage with ideas, opinions, information, and meaning represented in their collections. They make decisions about those ideas and information, and some of those decisions place librarians in ethical dilemmas. As information professionals, librarians are charged with the responsibility of navigating the plurality and complexity of today's society and provide access to the world's wealth of information and conflicts. They have a respon- 
sibility to expose the different assumptions and perspectives on the world and on society.

As the two examples discussed above demonstrate, when it comes ethically challenging issues, the responses offered by a prominent classification system have been less than satisfactory. One reason for this could be that the editors have looked to professional codes of ethics, by which they have been told to stay neutral and do the right thing. Such ethical advice is not of much help, and the editors have no other choice than merely to follow their own convictions and preferences. This has led to a situation where ethnicity and race has been equated and where they have attempted to merely accommodate a system's Christian bias to the contemporary society. This is an unfortunate situation. Classifications are a serious matter, and they do harm if not done properly. Editors and managers of major classification systems ought to take this ethical and epistemological responsibility seriously; they ought to be held responsible for the ethical choices they make.

To help libraries and librarians navigate the ethical and epistemic decisions they make, the value of the domain/practice cannot be overemphasized. By placing their decisions within the standards, norms, and authority of the practice, libraries and librarians could regain the authority they have sacrificed in the name of presumed neutrality.

To address the ethical dilemmas in the two examples, one should not ask: how do I do the right thing and remain neutral? The question should have been: what are the internal goods and standards of excellence of the relevant practices? To advance the conversation, editors of the system could address questions such as: which practice supports the equation of race and ethnicity? Which practice supports the Christian bias as a representation of the world's religions? The answers to those questions present the system's ethical foundation.

To forward discourses about libraries and library classifications, it may help to remember Rawls's fundamental charge that: "Justice is the first virtue of social institutions" (Rawls 1999, 3). To move the foundation of classification work from its prior absolutistic and essentialistic conceptual bases, it was argued that the ontic and epistemic foundation of classification should be found in relativistic and pragmatic philosophies. It now time to take that project one step further and ground libraries and library classification in sound moral philosophies to create just, fair and good libraries and library classifications.

\section{Notes}

1 Article 19 states that: "Everyone has the right to freedom of opinion and expression; this right includes freedom to hold opinions without interference and to seek, receive and impart information and ideas through any media and regardless of frontiers." The United Nations Universal Declaration of Human Rights is accessible at: http://www.un.org/en/documents/udhr/index.shtml

2 This title of the table remains in the $23^{\text {rd }}$ edition of DDC.

\section{References}

ALA. 2008. Code of ethics of the American Library Association. Available http://www.ala.org/advocacy/proethics/code ofethics/codeethics.

Beghtol, Clare. 2005. Ethical decision-making for knowledge representation and organization systems for global use. Journal of the American Society for Information Science and Technology 56: 903-12.

Beghtol, Clare. 2008. Professional values and ethics in knowledge organization and cataloging. Journal of information ethics 17 no. 1: 12-19.

Berman, Sanford. 1971. Prejudices and antipathies: a tract on the LC Subject Heads concerning people. Jefferson, NC: MacFarland \& Co.

Blackburn, Simon. 2001. Ethics: a very short introduction. Oxford: Oxford University Press.

Bowker, Geoffrey C. and Star, Susan Leigh. 1999. Sorting things out: classification and its consequences. Cambridge, MA: MIT Press.

Broadfield, A. 1946. The philosophy of classification. London: Grafton.

Brubaker, Jana. 2002. Ambiguous authorship and uncertain authenticity: a cataloger's dilemma. Cataloging and classification quarterly 34 no. 4: 19-30.

Cohen, Stewart. 1988. How to be a fallibilist. Philosophical perspectives 2: 91-123.

Dupré, John. 2006. Scientific classification. Theory, culture and society 23 no. 2-3: 30-2.

Ess, Charles. 2009. Digital media ethics. Cambridge, UK: Polity.

Fallis, Don. 2007. Information ethics for the twenty-first century library professionals. Library hi tech 25: 23-36.

Feinberg, Melanie. 2008. Classification as communication: properties and design PhD dissertation. Washington: University of Washington. Available https://www..school.utexas. edu/ feinberg/Feinberg\%20dissertation.pdf.

Feinberg, Melanie. 2011. Organization as expression: classification as digital media. In Aspray, William and Winget, Megan A., eds. Digital media. Lanham: Scarecrow Press, pp. 115-34.

Feinberg, Melanie. 2012. Synthetic ethos: the believability of collections at the intersection of classification and curation. The information society 28: 329-39.

Fricke, Martin, Mathiesen, Kay and Fallis, Don. 2000. The ethical presupposition behind the Library Bill of Rights. Library quarterly 70: 468-91. 
Furner, Jonathan. 2007. Dewey deracialized: a critical race-theoretic perspective. Knowledge organization 24 : 144-68.

Green, Rebecca. 2006. A new view of religion. 025.431: the Dewey blog. Available http://ddc.typepad.com/ 025431/2006/07/a_new_view_of_r.html

Hjørland, Birger. 2004a. Domain analysis in information science. In: Encyclopedia of library and information science. New York: Marcel Dekker.

Hjørland, Birger. 2004b. Social and cultural awareness and responsibility in library, information and documentation studies. In Rayward, Boyd, Hansson, Joacim and Suominen, Vesa, eds. Aware and responsible. Lanham, MD: Scarecrow Press, pp. 71-91.

Hjørland, Birger and Albrechtsen, Hanne. 1995. Toward a new horizon in information science: domain-analysis. Journal of the American Society for Information Science 46: 400-25.

IFLA. 2002. The Glasgow declaration on libraries, information services and intellectual freedom. Available http://www.ifla. org/publications/the-glasgow-declaration-on-librariesinformation-services-and-intellectual-freedom

Mai, Jens-Erik. 2005. Analysis in indexing: document and domain centered approaches. Information processing and management 41: 599-611.

Mai, Jens-Erik. 2011. The modernity of classification. Journal of documentation: 710-30.

MacIntyre, Alasdair. 1998. A short history of ethics: a history of moral philosophy from the homeric age to the twentieth century. London: Routledge.

MacIntyre, Alasdair. 2007. After virtue: a study in moral theory. Notre Dame, IN: University of Notre Dame Press.

McIlwaine, Ia C. and Mitchell, Joan S. 2006. The new ecumenism: exploration of a DDC/UDC view of religion. In Budin, Gerhard, Swertz, Christian and Mitgutsch, Konstantin, eds. Knowledge organization for a global learning society: proceedings of the ninth international ISKO conference, Vienna, Austria. Advances in knowledge organization 10. Würzburg: Ergon Verlag, pp. 323-30.

Miksa, Francis. 1998. The DDC, the universe of knowledge, and the post-modern library. Albany, NY: Forest Press.
Miksa, Francis. 2009. A review article: Chan, Taylor, and the future of cataloging texts. Library quarterly 79: pp. 131-43.

Nagel, Thomas. 1986. The view from nowhere. Oxford: Oxford University Press.

Nunberg, Geoff. 2004. Going nucular. Language, politics, and culture in confrontational times. New York, NY: PublicAffairs.

Oh, Dong-Geun and Yeo, Ji-Suk, 2001. Suggesting an option for DDC class religion (200) for nations in which religious diversity predominates. Knowledge organization 28: 75-84.

Olson, Hope A. 2002. The power to name: locating the limits of subject representation in libraries. Dordrecht, Netherlands: Kluwer Academic.

Shirky, Clay. 2005. Ontology is overrated: categories, links, and tags. Available http://www.shirky.com/writings/ontolo gy_overrated.html.

Talja, Sanna. 2005. The domain analytic approach to scholars' information practices. In Fisher, Karen, Erdelez, Sanda and McKechnie, Lynne, eds. Theories of information behavior: a researcher's guide. Medford, NJ. Information Today.

Tennis, Joseph. 2003. Two axes of domains for domain analysis. Knowledge organization 30: 191-5.

Rachels, James and Rachels, Stuart. 2012. The elements of moral philosophy. New York, NY: McGraw-Hill.

Rawls, John. 1999. A social theory of justice. Cambridge, MA: Harvard University Press.

Reed, Baron. 2002. How to think about fallibilism. Philosophical studies 107: 143-157.

Weinberger, David. 2007. Everything is miscellaneous: the power of the new digital disorder. New York: Times.

Wiegand, Wayne A. 1996. Irrepressible reformer: a biography of Melvil Dewey. Chicago: American Library Association.

Wiegand, Wayne A. 1998. The 'Amherst method': the origins of the Dewey Decimal Classification scheme. Libraries \& culture 33: 175-94.

Wilson, Patrick. 1983. Second-hand knowledge: an inquiry into cognitive authority. Westport, Conn.: Greenwood. 